\title{
Panel Cointegration and Pooled Mean Group Estimations of Energy-Output Dynamics in South Asia
}

\author{
*Anupam Das ${ }^{1}$, Murshed Chowdhury22, Muhammad Akhtaruzzaman ${ }^{3}$ \\ ${ }^{1}$ Mount Royal University, Canada \\ 2University of Manitoba, Canada \\ ${ }^{3}$ Shahjalal University of Science and Technology, Bangladesh \\ *adas@mtroyal.ca
}

\begin{abstract}
This study employs the panel cointegration and pooled mean group (PMG) techniques to examine the long run relationships between energy consumption and GDP for 5 South Asian countries from 1981 to 2009. Unit root and panel cointegration tests find a long run relationship between energy consumption and GDP after allowing for country-specific effect. Furthermore, we use the PMG technique to identify the magnitude of this relationship. Our results are consistent with the theory that suggests a role of energy use in GDP. On average, a $1 \%$ increase in energy consumption leads to a $0.61 \%$ increase in the long run GDP in South Asia from 1981 to 2009. Hence, it is apparent that energy is an important component to maintain the economic activities in these countries. These results have important implications for policy makers of South Asian countries which have experienced magnificent growth performance along with a sharp rise in consumption demand for energy in last few decades.
\end{abstract}

Keywords: Energy consumption, growth, South Asia, Panel cointegration, Pooled mean group

\section{Introduction and Literature Review}

With the rise in manufacturing and service sectors, the relationship between economic growth and energy consumption in developing countries has been of high interest in recent years. Since the early 1980's, the emerging South Asian countries have drawn an eminent attention to its magnificent growth performance. During the same time, the consumption demand for energy also rose sharply in this region. Average growth rates of output and energy consumption were at least $4.5 \%$ and $3.0 \%$ respectively in the major economies in South Asia from 1981 to 2009 (see table 1). As a result, the question of whether energy consumption is significantly contributing to output growth has been crucially intriguing for this region. Such an investigation on the role of energy consumption is important to formulate energy and environmental policies. If energy consumption is found to be helpful in promoting economic growth than any policy that encourages a reduction in energy consumption may have a negative impact on economic growth and vice versa.

Table 1: Average Growth Rates of GDP and Energy Use in South Asia: 1981-2009

\begin{tabular}{lll}
\hline Country & Average Growth in Output & Average Growth in Energy Use \\
\hline Bangladesh & $4.5 \%$ & $4.5 \%$ \\
India & $6.0 \%$ & $4.0 \%$ \\
Nepal & $5.0 \%$ & $3.0 \%$ \\
Pakistan & $5.0 \%$ & $4.5 \%$ \\
Sri Lanka & $5.0 \%$ & $3.0 \%$ \\
\hline
\end{tabular}

Source: World Bank (2011)

The literature on energy-growth relationship dates back to 1970s. Despite a voluminous work in this area, the relationship between energy consumption and the economic performance of developing countries is still not conclusive. Generally speaking, four broad conclusions can be drawn from empirical literature (Apergis and Payne, 2011; Fuinhas and Marques, 2012): a) the growth hypothesis: that energy consumption causes economic growth, b) the conservation hypothesis: that economic growth causes a rise in energy use, c) the feedback hypothesis: that there exists a bi-directional causality between energy use and economic growth, d) 
the neutrality hypothesis: that there is no statistically significant relationship between these two variables. Table 2 provides a summary of these results.

Time series studies on South Asian economies also produced similar results, which are summarized in table 3.

Table 2: Causal Relationship between Energy Consumption and Economic Growth: Summery of Literature Review

\begin{tabular}{|c|c|c|}
\hline Study & Country & Result \\
\hline Kraft and Kraft (1978) & USA & output $\rightarrow$ energy consumption \\
\hline Akarca and Long (1979) & USA & energy consumption $\rightarrow$ output \\
\hline Yu and Hwang (1984) & USA & no causality \\
\hline Hwang and Gum (1992) & Taiwan & output $\leftrightarrow$ energy consumption \\
\hline Murray and Nan (1992) & Turkey & energy consumption $\rightarrow$ output \\
\hline Cheng and Lai (1997) & Taiwan & output $\rightarrow$ energy consumption \\
\hline Fatai et al. (2002) & New Zealand & no causality \\
\hline Glasure (2002) & Korea & output $\leftrightarrow$ energy consumption \\
\hline Hondroyannis et al. (2002) & Greece & output $\leftrightarrow$ energy consumption \\
\hline Soytas and Sari (2003) & Turkey & energy consumption $\rightarrow$ output \\
\hline Ghali and El-Sakka (2004) & Canada & output $\leftrightarrow$ energy consumption \\
\hline Shiu and Lam (2004) & China & energy consumption $\rightarrow$ output \\
\hline Lee and Chang $(2005 ; 2007)$ & Taiwan & energy consumption $\rightarrow$ output \\
\hline Yoo (2006) & Korea & output $\leftrightarrow$ energy consumption (oil) \\
\hline Bowden and Payne (2009) & USA & energy consumption $\rightarrow$ output \\
\hline Chiou-Wei et al. (2008) & Turkey & output $\rightarrow$ energy consumption \\
\hline Karanfil (2008) & Taiwan & energy consumption $\rightarrow$ output \\
\hline Zhang and Cheng (2009) & China & output $\rightarrow$ energy consumption \\
\hline Bartleet and Gounder (2010) & Nigeria & output $\rightarrow$ energy consumption \\
\hline Ouedraogo (2010) & Burkina Faso & output $\leftrightarrow$ energy consumption \\
\hline Payne and Taylor (2010) & USA & no causality (nuclear energy and output) \\
\hline Suleiman (2010) & Greece & energy consumption $\rightarrow$ output \\
\hline Tsani (2010) & New Zealand & output $\rightarrow$ energy consumption \\
\hline Kouakou (2011) & Cote D'Ivoire & output $\leftrightarrow$ energy consumption \\
\hline Payne (2011a) & USA & $\begin{array}{l}\text { energy consumption } \rightarrow \text { output } \\
\text { no causality (coal and output) }\end{array}$ \\
\hline Payne (2011b) & USA & $\begin{array}{l}\text { output } \rightarrow \text { energy consumption (natural gas) } \\
\text { energy consumption (petroleum) } \rightarrow \text { output }\end{array}$ \\
\hline Vacchione (2011) & Italy & output $\rightarrow$ energy consumption (electricity) \\
\hline Wang et al. (2011) & China & energy consumption $\rightarrow$ output \\
\hline Lim and Yoo (2012) & Korea & output $\leftrightarrow$ energy consumption (natural gas) \\
\hline Wolde-Rufael (2012) & Taiwan & no causality (nuclear energy and output) \\
\hline
\end{tabular}

It is evident from the literature review in table 2 and 3 that empirical studies on causal relationship between energy consumption and economic growth failed to produce any unanimous result even for the same country. 
Table 3: Causal Relationship between Energy Consumption and Economic Growth: Summery of Literature Review for South Asian Countries

\begin{tabular}{lll}
\hline Study & Country & Result \\
\hline Yu and Choi (1985) & Sri Lanka & energy consumption $\rightarrow$ output \\
Masih and Masih (1996) & India & energy consumption $\rightarrow$ output \\
Masih and Masih (1996) & Pakistan & output $\leftrightarrow$ energy consumption \\
Cheng (1999) & India & output $\rightarrow$ energy consumption \\
Asafu-Adjaye (2000) & India & energy consumption $\rightarrow$ output \\
Aqeel and Butt (2001) & Pakistan & output $\rightarrow$ energy consumption \\
Soytas and Sari (2003) & India & No causality \\
Morimoto and Hope (2004) & Sri Lanka & energy consumption $\rightarrow$ output \\
Paul and Bhattacharjee (2004) & India & output $\leftrightarrow$ energy consumption \\
Mozumder and Marathe (2007) & Bangladesh & output $\rightarrow$ energy consumption \\
Heo et al. (2011) & India & energy consumption $\rightarrow$ output \\
Paul and Uddin (2011) & Bangladesh & output $\rightarrow$ energy consumption \\
\hline
\end{tabular}

Despite a number of time series investigations on energy consumption and economic growth, any specific panel-based study on South Asia is conspicuously absent. In recent years, South Asia has shown an interesting pattern of high output growth along with a sharp rise in energy consumption (Paul and Uddin, 2011). While the demand for energy has been rising boisterously, the supply of energy is yet to meet the demand (Noor and Siddiqi, 2010). Furthermore, environmental degradation and global warming have forced emerging countries of South Asia to adopt energy conservation policies which may have detrimental effect on their output growth. Hence, policy makers have raised a number of questions, such as: i) does energy consumption foster output growth in South Asia? ii) If so, how sizeable the magnitude of energy use-growth nexus is? ii) Are emerging countries from South Asia ready to embark the energy conservation policy? These questions are important to researchers and policy makers, and therefore, in order to formulate energy-related policies in South Asia a panel data approach is desired to reevaluate the relationship between energy consumption and economic growth in one of the most emerging regions of the developing world. To that end, this exercise employs a dataset of 5 South Asian countries to identify the long run relationship between energy consumption and output over the period of 1981 to 2009. Countries included in our dataset are: Bangladesh, India, Nepal, Pakistan and Sri Lanka. To find this relationship, we use following procedures: first, we employ a battery of unit root tests developed by Maddala and Wu (1999), Levin et al. (2002), and Im et al. (2003) to identify the level of integration among macroeconomic variables. To preview, all relevant variables are nonstationary at level and stationary at first-difference. Based on these results, we use a panel cointegration technique proposed by Pedroni (2004) and find the presence of long-run cointegrating relationships between energy consumption and GDP. Finally, we employ two recently developed methods for analyzing the dynamic panel data: the mean group (MG) and the pooled mean group (PMG) estimations. To our knowledge, this long run estimation of the energy-growth relationship for a panel of South Asian countries is unique. The remainder of the paper is organized as follows. Section 2 discusses different econometric techniques that are used in this paper. Section 3 presents and analyzes results and section 4 draws the conclusion.

\section{Methodology}

It has been shown in the earlier section that time series research on South Asian countries were not successful in producing any unanimous result on the relationship between energy consumption and economic growth. Numerous reasons, such as small sample size, and mis-specified econometric modeling could be held responsible for such inconclusive results (Huang et al., 2008; Ozturk, 2010). Huang et al. (2008: 43) argued that most of the empirical literature based on time series investigation used 30 to 40 years data and thus, produced results with low statistically testing power. Deficiency of inadequate sample size could be unraveled by using different panel techniques. Recent studies therefore emphasized on panel estimation procedures (Lee, 2005; Chen et al., 2007; Lee and Chang, 2007; Huang et al., 2008; Apergis and Payne, 2009, 2012). This study, based on panel data approach, attempts to address these issues. The behavioral equation 
estimated in our study relies heavily on the basic formation of Solow-type neoclassical growth equation, where output $(\ln G D P)$ is assumed to be determined by capital (lncap) and labor force (lnemp). Basic Solow equation is modified by incorporating energy consumption (lneng) as an independent variable. Therefore, our behavioral equation becomes:

$$
\ln G D P_{i t}=f\left(\ln c a p_{i t}, \ln e m p_{i t}, \ln e n g_{i t}\right)
$$

This equation is estimated for a panel of 5 South Asian countries over the period 1981 to 2009. Countries in the dataset are Bangladesh, India, Nepal, Pakistan and Sri Lanka. Yearly data of GDP and energy consumption have been collected from the World Development Indicators (WDI). Data on capital is collected from the UN Data. The other variable, i.e. labor force is proxied by the number of people over 15 years old. Data on this variable is gathered from the UNCTAD.

Tests for Unit Root: Our panel dataset has a large $T$ of 30 years and therefore, existence of unit roots in macroeconomic variables could be a real possibility. Hence, it is important to test for stationarity. To verify whether time series variables contain unit root, we employ three different yet popular tests: Maddala and Wu (1999) (MW), Levin et al. (2002) (LL) and Im et al. (2003) (IPS) tests. The LL tests are based on homogeneity of the autoregressive parameter, while the IPS tests are based on heterogeneity of autoregressive parameters. Thus, no pooling regressions are associated with IPS tests. MW tests, on the other hand, are based on Fishertype unit root tests that are not restricted to the sample sizes for different samples (Maddala and Wu, 1999). We use three different tests to confirm our results. Maddala and Wu (1999) argue that "...other conservative tests (applicable in the case of correlated tests) based on Bonferroni bounds have also been found to be inferior to the Fisher test." (pp: 650). Results from all these tests are given in table 4. The selection of the appropriate lag length was made using the Schwarz Bayesian Information Criterion. Unanimous results from all three unit root tests suggest that $\ln G D P$, lncap and lneng are non-stationary at level and stationary at first difference. The null hypothesis of non-stationarity was also not rejected by any of the three tests for the fourth variable, i.e. lnemp. However, this null hypothesis was rejected by two out of three tests for the first difference of lnemp. These results, therefore, suggest that none of the variables in our dataset are $I(2)$ or higher level of integration.

Table 4: Results from Panel Unit Root Tests

\begin{tabular}{llll}
\hline Variable & Maddala and Wu (1999) & Levin et al. (2002) & Im et al. (2003) \\
\hline $\ln G D P$ & 3.39 & 0.50 & 2.29 \\
$\Delta \ln G D P$ & $41.48^{* * *}$ & $-3.39^{* * *}$ & $-4.80^{* * *}$ \\
$\ln c a p$ & 8.67 & -1.55 & 8.67 \\
$\Delta \ln c a p$ & $37.37^{* * *}$ & $-3.34^{* * *}$ & $37.37^{* * *}$ \\
$\ln e m p$ & 3.00 & -1.20 & 3.00 \\
$\Delta \ln e m p$ & $17.86^{*}$ & 0.76 & $17.86^{*}$ \\
$\ln e n g$ & 5.33 & 0.27 & 0.84 \\
$\Delta \ln e n g$ & $43.61^{* * *}$ & $-5.99^{* * *}$ & $-5.18^{* * *}$ \\
\hline
\end{tabular}

Notes: 1) ${ }^{* * *}$ and ${ }^{*}$ imply levels significance at $1 \%$ and $10 \%$ respectively. 2) Null hypothesis for all three tests is that the series contains unit roots. Based on these results, we employ panel cointegration techniques that are appropriate for our study.

Pedroni (2004): Tests for Cointegration: Cointegration test, proposed by Pedroni (2004), allows for heterogeneity in the intercepts and slopes of the cointegrating equation, and therefore can be considered as a better technique (Murthy, 2007). Additionally, it also overcomes the problem of a small sample size and more than one cointegrating relationships. This test is based on the estimated residuals from the following long-run model:

$y_{i t}=\alpha_{i}+\sum_{j=1}^{m} \beta_{j i} X_{j i t}+u_{i t}$ 
where $u_{i t}=\rho_{i} u_{i(t-1)}+w_{i t}$ are the estimated residuals from the panel regression. In our case, the equation (4) can be elaborates as:

$(\ln G D P)_{i t}=\alpha_{i}+\beta_{i}(\ln e n g)_{i t}+\delta_{i}(\ln c a p)_{i t}+\gamma_{i}(\ln e m p)_{i t}+\theta_{i t}+u_{i t}$

for $i=1, \ldots, N$ and $t=1, \ldots, \mathrm{T}$. While the null hypothesis is no cointegration, Pedroni test reports seven alternative statistics: four of them are based on the within-dimension (panel tests) test while the other three are based on between-dimension (group tests) approach. Pedroni's long run heterogeneous panel cointegration test identifies the existence of long run relationship between variables, however, does not provide the magnitude of this relationship. Thus, we employ two recently developed econometric techniques, i.e. MG and PMG to identify the appropriate sign and the size of the energy coefficient in the long run output equation.

Mean Group (MG) and Pooled Mean Group (PMG): The literature on cointegrated panels has emerged in recent years. Pedroni (2000) proposes the group mean fully modified ordinary least square technique (GMFMOLS) that allows for heterogeneity in the cointegrating vector. In a recent paper, Noor and Siddiqi (2010) use the GM-FMOLS technique to identify the relationship between energy consumption and output in South Asia. Their results suggest a negative relation between these variables in the long-run. While this technique requires fewer assumptions than other panel approaches, the GM-FMOLS is relatively inefficient if the long run cointegrating vector is homogeneous across countries (Roudet et al, 2007). Moreover, GM-FMOLS results produce an average of the individual cointegrating vectors, which may be potentially different from the average. The pooled mean group approach (PMG), on the other hand, solves this problem by assuming homogeneity of the individual cointegrating vector across countries.PMG technique proposed by Pesaran et al. (1999) gained substantial popularity among researchers since it pools long run relationships between countries and short run dynamics are flexible and unrestricted across panels. A detailed discussion on these techniques is given in Asteriou (2009). Both MG and PMG are appropriate techniques for analyzing panel data with large $T$ and cross-section dimensions. MG procedure derives the long run parameter of a panel by averaging individual country-specific long run parameters from ARDL model. The general framework of an ARDL model is:

$\alpha_{i}(L) y_{i t}=\beta_{i}(L) x_{i t}+\delta_{i} z_{i t}+u_{i t}$

where $i=1, \ldots, N$. The long run parameter for individual country $i$ is:

$\theta_{i}=\frac{\beta_{i}(1)}{\delta_{i}(1)}$

The MG estimator for the whole panel is:

$\theta=\frac{1}{N} \sum_{i=1}^{N} \hat{\theta}_{i}$

PMG estimate assumes common long run coefficients while allowing for differences in short run dynamics and error-correction coefficients across countries. While MG approach is less restrictive than PMG estimator, PMG estimator is consistent and more efficient when the assumption of common long run coefficient is valid (Das, 2011). Thus, our estimates are unbiased from any country specific effect and less restrictive than fixed effects. Since PMG involves both pooling and averaging, it can be considered as an intermediate estimator between dynamic fixed effect (DFE) and MG (Martínez-Zarzoso and Bengochea-Morancho, 2004). The generalized form of the PMG estimation is represented by equation 7. The variable $y$ is $\ln G D P$, where, $x_{i j}$ is the vector of non-stationary variables; $z_{i, j}$ is the vector of stationary variables; $\mu_{i}$ represents the fixed-effect; $\varepsilon_{i t}$ represents the vector of standard errors and $\theta_{i}$ is the error correction coefficient. $\beta_{i}{ }_{i}$ represents the long run parameters, and finally, $\delta_{i j}^{\prime}, \psi_{i j}^{\prime}$ and $\xi_{i j}^{\prime}$ represent country specific short-run coefficient vectors. 
$\Delta y_{i t}=\theta_{i}\left(y_{i, t-1}-\beta^{\prime}{ }_{i} x_{i, t-1}\right)+\sum_{j=1}^{m-1} \delta_{i j}^{\prime} \Delta y_{i, t-j}+\sum_{j=1}^{n-1} \psi^{\prime}{ }_{i j} x_{i, t-j}+\sum_{j=1}^{q-1} \xi_{i j}^{\prime} z_{i, t-j}+\mu_{i}+\epsilon_{i t}$

All the short run dynamics and the error correction terms are free to vary and the estimation of this model is by maximum likelihood.

\section{Results and Analysis}

Panel Cointegration Results: Table 5 reports the results of Pedroni (2004) cointegration test. Except for panel $\rho$-statistics and group $\rho$-statistics, all other statistics significantly reject the null hypothesis of no cointegration. In fact, Pedroni (2004) showed that the two statistics that have better small sample properties are panel-ADF and group-ADF. These two statistics are thus more reliable. In our results, the null hypothesis non-stationarity is rejected at $1 \%$ level and $10 \%$ level by the panel-ADF statistics and group-ADF statistics respectively. Therefore, it can be argued that variables in our behavioral equation move together in the long run. In other words, after allowing for country-specific effect, there is a long run relationship between energy consumption and GDP in 5 South Asian countries. The next step is to estimate the magnitude of such a relationship by using PMG technique.

Table 5: Results from Panel Cointegration Tests

\begin{tabular}{lll}
\hline & Statistics & Probabilities \\
\hline Panel $v$-statistics & $3.57^{* * *}$ & 0.000 \\
Panel $\rho$-statistics & -1.01 & 0.239 \\
Panel $P P$-statistics & $-3.85^{* * *}$ & 0.000 \\
Panel $A D F$-statistics & $-2.92^{* * *}$ & 0.006 \\
Group $\rho$-statistics & 0.35 & 0.375 \\
Group $P P$-statistics & $-2.29^{* *}$ & 0.029 \\
Group $A D F$-statistics & $-1.37^{*}$ & 0.056 \\
\hline
\end{tabular}

Notes: $* * * * *$ and $*$ imply significance levels at $1 \%, 5 \%$ and $10 \%$ respectively

MG and PMG Estimations Results: Results from both MG and PMG estimations are presented in table 6. It is important to identify if these results are consistent. Pesaran et al. (1999) argue that MG estimator is always consistent. Therefore, we determine the consistency of PMG estimator by testing it against the MG estimator. Applying the Hausman test, we find that the null hypothesis of common coefficients between MG and PMG estimators is not rejected. Hence, PMG results are the appropriate ones, and should be interpreted. Not surprisingly, coefficients from the MG estimators are mostly insignificant and sometimes large. The error correction term from the PMG estimator is significant with a value of negative 0.15 . This suggests that around $15 \%$ of the deviation from the long-term relationship is corrected in the first year. The long run coefficient of investment variable (i.e. Incap) is positive and significant at better than the $1 \%$ level. The coefficient for labor is negative but insignificant. The PMG estimates suggest a strong positive relationship among energy consumption and GDP in the long run. The magnitude of the lneng coefficient, which is also significant at $1 \%$ level, is approximately 0.61 . In effect, for South Asia, on average, a $1 \%$ increase in energy consumption leads to a $0.61 \%$ increase in long run GDP. Hence, our results from estimated panel cointegration and PMG procedure suggest a positive long run relationship between energy consumption and GDP in South Asia over the period of 1981 to 2009. In other words, evidence of energy-led growth is more prominent in South Asian economies. This result seems reminiscent of what has been found by other panel-based empirical studies such as Lee (2005), Chen et al. (2007) and Apergis and Payne (2009). Our results also support the findings of some time series studies focusing on South Asian countries (See for example, Yu and Choi (1985), Masih and Masih (1996), Asafu-Adjaye (2000) and Morimoto and Hope (2004)). Therefore, we argue that the benefit of energy use is greater than the cost in South Asian economies. Energy conservation policies in these countries may actually affect the economic growth adversely. 
Table 6: Results from MG and PMG Estimations for South Asia

\begin{tabular}{lll}
\hline Dependent Variable: $\ln G D P$ & & \\
\hline Explanatory Variables & $\begin{array}{l}\text { Mean Group (MG) } \\
\text { Long Run Coefficients }\end{array}$ & Pooled Mean Group (PMG) \\
\hline lncap & $0.869^{* * *}(2.77)$ & $0.615^{* * *}(0.06)$ \\
$\ln e m p$ & $-0.179(1.00)$ & $-0.384(0.03)$ \\
$\ln e n g$ & $0.171(0.69)$ & $0.609^{* * *}(0.18)$ \\
& Short Run Coefficients & \\
Error Correction & $-0.209^{* * *}(0.08)$ & $-0.151(0.08)$ \\
$\Delta \operatorname{lngdp} p_{-1}$ & $-0.385^{* * *}(0.15)$ & $-0.328^{* *}(0.14)$ \\
$\Delta \operatorname{lng} p_{-2}$ & $-0.048(0.11)$ & $0.048(0.11)$ \\
$\Delta \ln c a p$ & $0.032(0.04)$ & $0.057(0.05)$ \\
$\Delta \ln l a b$ & $-1.351^{* * *}(0.51)$ & $-0.785(0.54)$ \\
$\Delta \ln l a b-1$ & $-0.509(0.84)$ & $-0.847(0.86)$ \\
$\Delta \ln e n g$ & $0.211(0.18)$ & $0.214(0.22)$ \\
Constant & $-0.075(1.82)$ & $1.698^{*}(0.90)$ \\
Number of Observations & 130 & 130 \\
Number of Groups & 5 & 5 \\
Hausman Test & $\chi^{2}: 1.38$ & \\
Ho: Difference in coefficients & Prob $>\chi^{2}: 0.71$ & \\
not systematic & & \\
\hline
\end{tabular}

Notes: 1$)^{* * *, * *}$ and * imply significance levels at 1\%, 5\% and 10\% respectively. 2) Standard errors are in the parenthesis.

\section{Conclusion}

With the onset of globalization, there has been a significant demand for energy from the manufacturing and service sectors of South Asian countries. This was coupled with spectacular economic growth in last few decades. However, large economies from this region have also been facing the challenges of environment and energy efficiency (Paul and Uddin, 2011). Although earlier studies have investigated the relationship between energy and GDP for individual countries from South Asia, quite disappointedly, very little has been done for the region as a whole. Our paper attempts to fill this gap in the literature by examining the long run relationship between energy consumption and income for a panel of 5 major South Asian economies over the period of 1981 to 2009. These countries are: Bangladesh, India, Nepal, Pakistan and Sri Lanka. We employ both panel cointegration (Pedroni, 2004) and PMG (Pesaran et al., 1999) to establish long run energy-output relationships in South Asia. Results from unit root tests and panel cointegration suggest that there exist long run cointegrating relationships among variables in our dataset. Additional results from PMG estimators helped up to identify the magnitude and the sign of energy coefficient in the output equation. We find that, on average, a $1 \%$ increase in energy consumption led to a $0.61 \%$ increase in long run GDP in South Asia from 1981 to 2009. Hence, the energy-led growth hypothesis seems to be working for South Asian countries. It is therefore clear that energy is an important component to maintain the economic activities in these countries. This study raises some additional questions which are interesting: 1) Does this result hold for other developing regions, such as Sub-Saharan Africa or Latin America and the Caribbean? 2) What are the effects of different types of energy on economic growth? These questions are important for a number of reasons. First, understanding the relationship between energy consumption and economic growth will help policy makers in developing countries in planning strategic energy investment (Vacchione, 2011). Second, different types of energy may have different causal and size of impacts on economic growth and environment. Therefore, understanding the economic and social impact of different types of energy is important to evaluate the effectiveness of energy and environmental policies. Hence, these questions are left for further research. 


\section{References}

Akarca, A. T. \& Long, T. V. (1979). Energy and Employment: A Time Series Analysis of the Causal Relationship. Resources and Energy, 2(2-3), 151-162.

Apergis, N. \& Payne, J. E. (2009). Energy Consumption and Economic Growth in Central America: Evidence from a Panel Cointegration and Error Correction Model. Energy Economics, 31(2), 211-216.

Apergis, N. \& Payne, J. E. (2011). Renewable and Non-renewable Electricity Consumption-Growth Nexus: Evidence from Emerging Market Economies. Applied Energy, 88(12), 5226-5230.

Apergis, N. \& Payne, J. E. (2012). A Global Perspective on the Renewable Energy Consumption-Growth Nexus. Energy Sources, Part B, 7(3), 314-322.

Aqeel, A. \& Butt, M. S. (2001). The Relationship between Energy Consumption and Economic Growth in Pakistan. Asia Pacific Development Journal, 8(2), 101-110.

Asafu-Adjaye, J. (2000). The Relationship between Energy Consumption, Energy Prices and Economic Growth; Time Series Evidence from Asian Developing Countries. Energy Economics, 22(6), 615-625.

Asteriou, D. (2009). Foreign Aid and Economic Growth: New Evidence from a Panel Data Approach for Five South Asian Countries. Journal of Policy Modeling, 31(1), 155-161.

Bartleet, M. \& Gounder, R. (2010). Energy Consumption and Economic Growth in New Zealand: Results from Trivariate and Multivariate Models. Energy Policy, 38(7), 3508-3517.

Bowden, N. \& Payne, J. E. (2009). The Causal Relationship between US Energy Consumption and Real Output: A Disaggregated Analysis. Journal of Policy Modeling, 31(2), 180-188.

Chen, S. T., Kuo, H. I. \& Chen, C. C. (2007). The Relationship between GDP and Electricity Consumption in 10 Asian Countries. Energy Policy, 35(4), 2611-2621.

Cheng, B. S. \& Lai, T. W. (1997). An Investigation of Cointegration and Causality between Energy Consumption and Economic Activity in Taiwan. Energy Economics, 19(4), 435-444.

Cheng, B. S. (1999). Causality between Energy Consumption and Economic Growth in India: An Application of Cointegration and Error-Correction Modeling. Indian Economic Review, 34(1), 39-49.

Chiou-Wei, S. Z., Chen, C. \& Zhu, Z. (2008). Economic Growth and Energy Consumption Revisited- Evidence from Linear and Nonlinear Granger Causality. Energy Economics, 30(6), 3063-3076.

Das, A. (2011). External Resources and Savings Rate: A Pooled Mean Group Analysis for Developing Countries. Journal of Economics and Behavioral Studies, 3(1), 51-62.

Fatai, K., Oxley, L. \& Scrimgeour, F. (2002). Energy Consumption and Employment in New Zealand: Searching for Causality. Paper presented at NZAE Conference, Wellington, 26-28 June.

Fuinhas, J. A. \& Marques, A. C. (2012). An ARDL Approach to the Oil and Growth Nexus: Portuguese Evidence. Energy Sources, Part B, 7(3), 282-291.

Ghali, K. H. \& El-Sakka, M. I. T. (2004). Energy Use and Output Growth in Canada: A Multivariate Cointegration Analysis. Energy Economics, 26(2), 225-238.

Glasure, Y. U. (2002). Energy and National Income in Korea: Further Evidence on the Role of Omitted Variables. Energy Economics, 24(4), 355-365.

Heo, J. Y., Yoo, S. H. \& Kwak, S. J. (2011). The Causal Relationship between Nuclear Energy Consumption and Economic Growth in India. Energy Sources, Part B, 6(2), 111-117.

Hondroyiannis, G., Lolos, S. \& Papapetrou, E. (2002). Energy Consumption and Economic Growth: Assessing the Evidence from Greece. Energy Economics, 24(4), 319-336.

Huang, B., Hwang, M. J. \& Yang, C. W. (2008). Causal Relationship between Energy Consumption and GDP Growth Revisited: A Dynamic Panel Data Approach. Ecological Economics, 67(1), 41-54.

Hwang, D.\& Gum, B. (1992). The Causal Relationship between Energy and GNP: the Case of Taiwan. Journal of Energy and Development, 3, 219-226.

Im, K.S., Pesearan, M. H. \& Shin, Y. (2003). Testing for Unit Roots in Heterogeneous Panels. Journal of Econometrics,115(1), 53-74.

Karanfil, F. (2008). Energy Consumption and Economic Growth Revisited: Does the Size of Unrecorded Economy Matter? Energy Policy, 36(8), 3029-3035.

Kouakou, A. K. (2011). Economic Growth and Electricity Consumption in Cote D'Ivoire: Evidence from Time Series Analysis. Energy Policy, 39(6), 3638-3644.

Kraft, J. \& Kraft, A. (1978). On the Relationship between Energy and GNP. Journal of Energy and Development, 3, 401-403. 
Lee, C. (2005). Energy Consumption and GDP in Developing Countries: A Cointegrated Panel Analysis. Energy Economics, 27(3), 415-427.

Lee, C. \& Chang, C. P. (2005). Structural Breaks, Energy Consumption, and Economic Growth Revisited: Evidence from Taiwan. Energy Economics, 27(6), 857-872.

Lee, C. \& Chang, C. P. (2007). Energy Consumption and GDP Revisited: A Panel Analysis of Developed and Developing Countries. Energy Economics, 29(6), 1206-1223.

Levin, A., Lin, C. \& Chu, C. J. (2002). Unit Root Tests in Panel Data: Asymptotic and Finite-Sample Properties. Journal of Econometrics, 108(1), 1-24.

Lim, H. J. \& Yoo, S. H. (2012). Natural Gas Consumption and Economic Growth in Korea: A Causality Analysis. Energy Sources, Part B, 7(2), 169-176.

Maddala, G. S. \& Wu, S. (1999). A Comparative Study of Unit Root Tests with Panel Data and a New Simple Test. Oxford Bulletin of Economics and Statistics, Special Issue, 631-652.

Martínez-Zarzoso, I. \& Bengochea-Morancho, A. (2004). Pooled Mean Group Estimation of an Environmental Kuznets Curve for $\mathrm{CO}_{2}$. Economics Letters, 82(1), 121-126.

Masih, A. M. M. \& Masih, R. (1996). Energy Consumption, Real Income and Temporal Causality; Results from a Multi-country Study Based on Cointegration and Error Correction Modeling Techniques. Energy Economics, 18(3), 165-183.

Morimoto, R. \& Hope, C. (2004). The Impact of Electricity Supply on Economic Growth in Sri Lanka. Energy Economics, 26(1), 77-85.

Mozumder, P. \& Marathe, A. (2007). Causality Relationship between Electricity Consumption and GDP in Bangladesh. Energy Policy, 35(1), 395-402.

Murray, D. A. \& Nan, G.D. (1992). The Energy and Employment Relationship: A Clarification. Journal of Energy and Development, 16(1), 121-131.

Murthy, N. R. V. (2007). Panel Cointegration Analysis: An Empirical Example, in Cointegration for the Applied Economist. In Rao, B. (ed.) Cointegration for the Applied Economics, 2, 222-256.

Noor, S. \& Siddiqi, M. W. (2010). Energy Consumption and Economic Growth in South Asian Countries: A CoIntegrated Panel Analysis. International Journal of Human and Social Sciences, 5(14), 921-926.

Ouedraogo, I. M. (2010). Electricity Consumption and Economic Growth in Burkina Faso: A Cointegration Analysis. Energy Economics, 32(3), 524-531.

Ozturk, I. (2010). A Literature Survey on Energy-Growth Nexus. Energy Policy, 38(1), 340-349.

Paul, B. P. \& Uddin, G. S. (2011). Energy and Output Dynamics in Bangladesh. Energy Economics, 33(3), 480487.

Paul, S. \& Bhattacharya, R. N. (2004). Causality between Energy Consumption and Economic Growth in India: A Note on Conflicting Results. Energy Economics, 26(6), 977983.

Payne, J. E. \& Taylor, J. P. (2010). Nuclear Energy Consumption and Economic Growth in the U.S.: An Empirical Note. Energy Sources, Part B,5(3), 301-307.

Payne, J. E. (2011a). On Biomass Energy Consumption and Real Output in the US. Energy Sources, Part B, 6(1), 47-52.

Payne, J. E. (2011b). US Disaggregate Fossil Fuel Consumption and Real GDP: An Empirical Note. Energy Sources, Part B, 6(1), 63-68.

Pedroni, P. (2000). Fully-Modified OLS for Heterogeneous Cointegrated Panels. In Advances in Econometrics: Nonstationary Panels, Panel Cointegration and Dynamic Panels, 15, 93-150.

Pedroni, P. (2004). Panel Cointegration; Asymptotic and Finite Sample Properties of Pooled Time Series Tests, with an Application to the PPP Hypothesis: New Results. Econometric Theory, 20(3), 597-625.

Pesaran, M. H., Shin, Y. \& Smith, R. (1999). Pooled Mean Group Estimation of Dynamic Heterogeneous Panels. Journal of the American Statistical Association, 94(446), 621-634.

Roudet, S., Saxegaard, M. \& Tsangarides, C. G. (2007). Estimation of Equilibrium Exchange Rates in the WAEMU: A Robustness Approach. IMF Working Paper, WP/07/194. Available at: http://cid.bcrp.gob.pe/biblio/Papers/IMF/2007/agosto/wp07194.pdf.

Shiu, A. \& Lam, L. P. (2004). Electricity Consumption and Economic Growth in China. Energy Policy, 32(1), 4754.

Soytas, U. \& Sari, R. (2003). Energy Consumption and GDP: Causality Relationship in G-7 Countries and Emerging Markets. Energy Economics, 25(1), 33-37.

Suleiman, S. (2010). Energy Consumption and Economic Growth: Causality Relationship for Nigeria. OPEC Energy Policy, 34(1), 15-24. 
Tsani, S. Z. (2010). Energy Consumption and Economic Growth: A Causality Analysis from Greece. Energy Economics, 32(3), 582-590.

Vacchione, G. (2011). Economic Growth, Electricity Consumption and Foreign Dependence in Italy between 1963-200. Energy Sources, Part B, 6(3), 304-313.

Wang, Y., Wang, Y., Zhou, J., Zhu, X. \& Lu, G. (2011). Energy Consumption and Economic Growth in China: A Multivariate Causality Test. Energy Policy, 39(7), 4399-4406.

Wolde-Raufael, Y. (2012). Nuclear Energy Consumption and Economic Growth in Taiwan. Energy Sources, Part $B,(1), 21-27$.

World Bank (2011). World Development Indicators, World Bank: Washington DC.

Yoo, S. H. (2006). Oil Consumption and Economic Growth: Evidence from Korea. Energy Sources, Part B, 1(3), 235-243.

Yu, E. S. H. \& Hwang, B.K. (1984). The Relationship between Energy and GNP: Further Results. Energy Economics, 6(3), 186-190.

Yu, E. S. H. \& Choi, J. Y. (1985). Causal Relationship between Energy and GNP: An International Comparison. Journal of Energy and Development, 10(2), 249-272.

Zhang, X. P. \& Cheng, X. M. (2009). Energy Consumption, Carbon Emissions, and Economic Growth in China. Ecological Economics, 68(10), 2706-2712. 